\title{
The impact of preservation method of lucerne forage on the digestibility of high grain racing or complete competition diets for horses
}

D G Thomas ${ }^{1}$, L A Tucker ${ }^{2}$

${ }^{1}$ Massey University, Palmerston North, New Zealand, ${ }^{2}$ LWT Animal Nutrition Ltd, Feilding, New Zealand

Email: lucy.tucker@xtra.co.nz

Introduction Previous research has shown that controlled fermented lucerne products have higher DE values, and other potential benefits, relative to dry lucerne chaff. Racing diets and high energy compound competition feeds for horses are typically formulated with higher levels of grain, which are associated with many problems in horses, including gastric ulceration, poor digestion, acidosis and gastric discomfort. Lucerne is associated with reducing the incidence of ulcers (Andrews et al., 2005; Nadeau, 2006), and feeding controlled fermented lucerne can increase intake time, improving the throughput of forage over a longer period of time. Lucerne contains a larger proportion of soluble carbohydrates (Fonnesbeck, 1968), making it more digestible than grass-based versions. Horses have been shown to retain lucerne in their gut for longer than oat straw, increasing overall diet (especially grain) digestibility (Cuddeford et al. 1995). Combining these factors, feeding lucerne ensures a more consistent supply of forage through the gut and, when fed alongside grainbased feed, improves the overall diet digestibility, as it maintains gut fill and optimises fermentation in the hind gut as well as diluting the potential negative impacts of starch overload and microflora imbalances. The following trial examined if feeding controlled fermented (CF) Lucerne in replacement for hay resulted in improvements in energy digestion when fed alongside either high grain racing diets or competition feeds for horses, on overall energy digestibility.

Materials and methods Ten thoroughbred-type non-racing horses were used to determine the effect of substituting CF lucerne (Fiber Pro, Fiber Fresh Feeds Ltd, Reporoa, New Zealand) for meadow hay chaff, in different proportions, alongside either a high grain racing diet (50\% barley, 50\% oats plus vitamin and mineral premix, with $33 \%$ DE from forage) or a commercial competition diet (Dunstans Sport Horse mix plus vitamin and mineral premix with 50\% DE from forage). Diets were formulated, to deliver the same amount of energy per day, based on a $500 \mathrm{~kg}$ horse not in work (NRC, 2007). Each horse received each of the forage-diet combinations for a seven day period during the trial in a latin square design, where CF lucerne increasingly replaced dry hay chaff. At the end of each seven day period, a faecal collection was made to determine energy digestibility. The results were used to identify any relationships between the amount of CF lucerne in the forage component of the diet and the overall energy of the whole diet. Any feed refused was weighed and recorded on a daily basis. Samples of both feed and faeces were analysed for dry matter and gross energy (by bomb calorimetry). Data was analysed by the GLM procedure of Unistat 5.5 (Unistat UK Ltd.).

Results For the high grain racing diet, the total DE of the entire diet increased linearly in relation to the amount of $\mathrm{CF}$ lucerne in the diet $\left(\mathrm{R}^{2}=0.9166\right.$ - see fig below). Retained energy $(\mathrm{MJ} / \mathrm{d})$ increased by $26 \%$ from $69.3 \mathrm{MJ} / \mathrm{d}(100 \%$ hay $)$ to $87.8 \mathrm{MJ} / \mathrm{d}$ (100\% CF lucerne). Digestible energy supplied by the whole diet increased by $8 \%$ from $12.9 \mathrm{MJ} / \mathrm{kg}(100 \% \mathrm{hay})$ to $14.1 \mathrm{MJ} / \mathrm{d}(100 \% \mathrm{CF}$ lucerne).

For the competition feed treatments, a polynomial (order 2) relationship was found for increasing levels of CF lucerne in both total diet $\mathrm{DE}\left(\mathrm{R}^{2}=0.50\right)$ and for the digestibility of the competition feed alone (as calculated by subtracting the DE contribution of the forage from the DE of the whole diet; $\mathrm{R}^{2}=0.52$ ). This data suggested that the optimum inclusion of $\mathrm{CF}$ lucerne in the diet is when it replaces $45 \%$ of the hay by weight, as this gave the highest numeric levels of retained energy, DE and the daily DE contribution of the grain only, when the forage contribution was excluded.

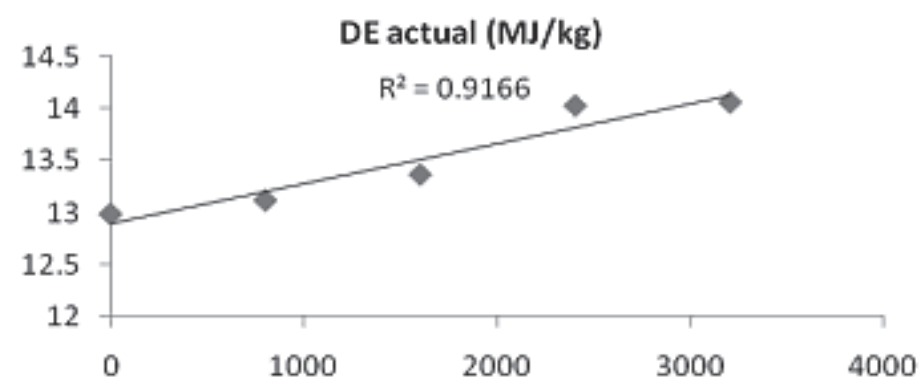

Conclusions CF lucerne had a positive impact on the digestible energy of high grain, racing-type diets. This forage could be used to increase the supply of energy to racing horses, and improving overall digestibility may help increase the efficiency of feed utilisation in the horse. For the competition diets such relationships were not as evident, possibly due to the less extreme nature of the feeding regime, with higher forage and lower grain inclusion in the daily ration. Hence the optimal inclusion level for substituting CF lucerne for dry hay chaff was $45 \%$. Both trials gave evidence to different degrees that, as per other reported research, feeding lucerne forages improved the digestibility of high grain diets compared to dry hay chaff.

\section{References}

Andrews F.M., Buchanan B.R., Elliot S.B., Clariday N.A. and Edwards L.H. 2005. Journal of Animal Science 83, E18-E21.

Cuddeford D., Pearson R.A., Archibald R.F. and Muirhead R.H. 1995. Animal Science 61, 407-417.

Fonnesbeck P.V. 1968. Journal of Animal Science 27, 1336-1344.

NRC 2007 Nutrient requirements of horses. National Academic Press, USA. 